\title{
PLACENTA ACCRETA SPECTRUM - A CASE SERIES
}

\section{Dr Medha Dadaji Davile}

\section{Dr Anil Charandas Humane*}

Dr Āshwini Kuchnur

\section{Assistant Professor, Department of Obstetrics and Gynaecology, Government Medical College \& Hospital, Nagpur,Maharashtra, India.}

Associate Professor, Department of Obstetrics and Gynaecology, Government Medical College \& Hospital, Nagpur,Maharashtra, India. ${ }^{\star}$ Corresponding Author

Junior Resident, Department of Obstetrics and Gynaecology, Government Medical College \& Hospital, Nagpur,Maharashtra, India.

ABSTRACT Morbidly adherent placenta is a major cause for massive obstetric hemorrhage, which leads to maternal morbidity and mortality. Most accepted hypothesis for etiology of placenta accreta spectrum is defect in the endometrial-myometrial interface which leads to failure of normal decidualization in the uterine scar, which allows abnormal deep infiltration of placental anchoring villi and trophoblast. Maternal morbidity and mortality can occur as a result of massive and sometimes life-threatening obstetric hemorrhage which often requires blood transfusion. It becomes exponential and life threatening when placenta previa is associated with placenta accreta spectrum. There are several risk factors for placenta accreta spectrum, most common being previous caesarian section. Antenatal diagnosis of placenta accreta is highly desirable as outcomes are optimized when timely delivery occurs at a tertiary care facility accustomed to handle such cases. Here we are reporting six cases of placenta accreta spectrum managed by conventional and expectant way at our tertiary care hospital. Methods: Study was carried out in Government Medical College \& Hospital, Nagpur. Case records of patients with placenta accreta syndrome between December 2019 and March 2020 were reviewed and analysed. Results: Six cases of placenta accreta syndrome were studied.100\% patients had history of previous caesarean section, 5 patients had associated placenta previa. One out of six patients one had history of dilatation and evacuation for missed abortion. 4 out of six underwent caesarean hysterectomy and 2 underwent conservative management with uterine preservation. Average blood loss was $2500 \mathrm{ml}$. Conservative management was successful in two patients. There was no maternal mortality in series. Conclusion : Among many risk factors, previous caesarean section is the most common. Therefore reducing rate of caesarean deliveries can reduce the prevalence of placenta accreta syndromes. Adherent placenta should be suspected in cases of previous caesarean with placenta previa, high parity, uterine curettage, and uterine surgeries.Conservative management should be reserved for selected patients. MRI is not mandatory for diagnosis of the condition.

KEYWORDS : placenta previa, placenta accreta, placenta increta, placenta percreta, hysterectomy

\section{INTRODUCTION:}

Placenta accreta spectrum(PAS) formerly called as morbidly adherent placenta is aberrant placenta characterized by abnormally implanted, invasive, adherence of the placenta including accreta, increta, percreta collectively called as accreta spectrum. This classification depends on depth of invasion.

Placenta accreta is one where abnormal villi are attached to myometrium. Placenta increta- abnormal villi are invading the myometrium. Placenta percreta - abnormal villi penetrate through the myometrium and or through the serosa. Clinically ratio of these variants is >70: 13: 5 respectively. Maternal morbidity and mortality can occur because of severe and sometimes life-threatening hemorrhage, which often requires blood transfusion. Rates of maternal death are increased in women with placenta accreta spectrum ${ }^{(1,2)}$. Additionally patients with accreta spectrum are more likely to require hysterectomy intraoperatively or during postoperative period and have longer hospital stays $\mathrm{s}^{(2)}$

The rates are increasing significantly, studies showing in 1970 and 1980, there were $l$ in 2510 to $l$ in 4017 compared to $l$ in 550 in 1982 to $2002^{(3)}$. The increasing rates of placenta accreta over last four decades is likely due to change in risk factors most likely increase in rates of caesarean section. Clinically, severe complication of PAS includes severe obstetric hemorrhage leading to DIC, iatrogenic injury to ureter, bladder, transfusion related lung injury, acute transfusion reaction, electrolyte imbalance and renal failure. In placenta accreta expected blood loss is $3000 \mathrm{ml}$ to $5000 \mathrm{ml}$ and maternal mortality rate is $6-7 \%{ }^{(4)}$.
Different methods have been implicated in the management of placenta accreta spectrum, ranging from uterine conservation and conventional hysterectomy. Conventional management of placenta accreta spectrum is caesarean hysterectomy with the placenta left in situ after delivery of the fetus(attemps at placental removal results in massive hemorrhage).Expectant management of placenta accrete spectrum involves leaving the placenta partially or totally in situ and monitoring for placental resorption.

We are reporting six cases treated in our hospital from December 2019 to June 2020 managed by both expectant and conventional approach.

\section{Case-1}

25 years G2PlLl with previous caesarean 2 years back, presented to the emergency department at 28 weeks 2 days with complaint of painless bleeding per vagina. On admission patient was haemodynamically stable. Per abdomen uterus size was corresponding, fetal heart was 150/min and on local examination, os closed and spotting was present, Inj tranexamic acid and Inj betamethasone was given. Ultrasonography with doppler showed placenta anterior and completely covering the os with multiple venous lacunae invading the myometrium.

At 30 weeks patient had bout of heavy bleeding and taken for emergency caesarean, abdomen opened by pfannenstiel incision and uterus by transverse curvilinear incision, a preterm female baby with weight of $1.2 \mathrm{kgs}$ was delivered and shifted to premature baby unit. Placenta was completely adhered to uterine wall with intact serosa. Inseparable placenta was kept in situ. Bilateral uterine, ovarian and 
internal iliac arteries ligation was done. Intraoperative blood loss was 2000 cc. 4 pints whole blood and 4 pints FFP given. Serial Beta HcG done on day 5, 7, 14, 21 were 5754, 3873, 2478, 1378 respectively. Patient was discharged on day 14 .

Ultrasonography done on day 14 showed bulky uterus with retained products of conception of $130 \mathrm{cc}$ without taking vascularity. Complete resorption of placenta was seen at about 14 weeks postdelivery.

\section{Case 2}

24 years old G2PlLl with previous caesarean 3 years back presented at 32 weeks of gestation with bleeding per vaginum. Patient was pale but haemodynamically stable. Per abdomen - uterus 34 weeks, breech, fetal heart was 140/min, per speculum os closed, bleeding present. Prior USG at 21 weeks was suggestive of placenta low lying with features of placenta accreta. Inj tranexamic acid, steroids were given. She was transfused with 2 pints of packed cell on haemoglobin of 7 gm\%. Active bleeding continued, patient was taken for emergency caesarean, abdomen was opened by midline vertical incision. Large venous lakes and tortous vessels were present over lower uterine segment invading bladder base, placenta percreta present with placental tissue invading the bladder base. While palpating fetal parts, one of venous lakes ruptured. Profuse bleeding was present, rent at venous lake was extended with fingers and preterm female baby $1.9 \mathrm{kgs}$ was delivered, obstetric hysterectomy done. Placental tissue removed as much as possible from bladder base,after defining the bladder margins, hemostatic sutures taken and pressure packing done, hemostasis achieved and abdomen closed in layers. Patient received intraoperatively 8 pints of WB, 8 FFP and 2 pints platelets, was on inotropic support for two days. Postoperatively, she received 3 pints of whole blood and got discharged on day 21 postoperatively.

Case 3

28 years old G3PlLlAl with previous caesarean 8 years back with 39 weeks gestation got admitted through OPD as a referred case. On ultrasonography placenta was anterior with two lobes, superior lobe showing indistinct zone at myometrial placental junction with placental tissue invading the myometrium. Patient was posted for elective caesarean. Abdomen opened by pfannensteil incision, e/o dilated vessels over anterior wall, uterus was opened by transverse curvilinear incision, a full term female baby of $2.9 \mathrm{kgs}$ was delivered with superior lobe of placenta adherent to the myometrium . Bilateral uterine arteries were ligated, uterotonics given, active bleeding was present from superior lobe of placenta, subtotal obstetric hysterectomy was done. Intraoperative blood loss was $2000 \mathrm{cc}$. Patient received 2 pints blood intraoperatively and 2 pints blood and FFP post operatively and was discharged on day 10 of delivery.Case 4: 26 years old patient G2P1Ll with previous caesarean two and half years back presented at 30 weeks 5 days of gestation with placenta previa in bleeding phase. Ultrasonography showed anterior placenta completely covering the os.

Patient was pale, uterus 32 weeks, with cephalic presentation fetal heart $130 \mathrm{bpm}$, mild uterine contractions were present. On local examination os was closed and bleeding present.

One pint of WB was given and posted for emergency caesarean, abdomen opened by pfannensteil incision and uterus by transverse curvilinear incision, a preterm female baby was born with birth weight of $1.2 \mathrm{kgs}$, placenta anterior and left lateral and completely covering the os, adhered to myometrium, cord was tied near the placenta, placenta kept in situ, devascularization was done. No active bleeding was present, uterus was closed, patient received 2 units blood and 2 units FFP. On day 14, ultrasonography was done showed bulky uterus with minimal vascularity. Complete resorption of placenta was seen at 13 weeks post delivery.
Case 5

26 years old female patient with previous caesarean 5 years back got admitted to emergency department at 33 wks as placenta previa in bleeding phase.On ultrasonography, placenta was posterolateral completely covering the os. Patient was haemodynamicaly stable , uterus was 34 weeks , cephalic, fetal heart was $134 / \mathrm{min}$, uterine contractions present. Local examination os closed, bleeding present. Emergency caesarean was done, abdomen opened by pfannensteil incision, uterus by transverse curvelinear incision female baby of $1.9 \mathrm{kgs}$ delivered. Placenta posterolateral and completely covering the os, adhered to myometrium more on left side, uterotonics were given and $b / 1$ uterine arteries ligated,active bleeding was present,obstetric hysterectomy done and bilateral internal iliac ligation done.Patient received 4 pints blood and 4 pints FFP, needed inotropic support during surgery, patient was in ICU postoperatively for 2 days, discharged on day 12 .

Case 6: 24 years old female patient with previous caesarean 3 years back got admitted at 28 weeks of gestation with diagnosis of placenta percreta .MRI findings showed placenta completely covering the os and invading the myometrium and serosal layer.There was loss of hypoechoiec clear zone between placenta and myometrium.Patient received steroids.conservative management was continued. Elective caesarean was done at 38 weeks of gestation, abdomen opened by median incision e/o placenta percreta present. Uterus opened by classical incision and full term female baby of $2.4 \mathrm{kgs}$ delivered. Bilateral internal iliac arteries were ligated and cord tied near placenta,placenta kept in situ and uterus was closed. Patient received 4 pints blood and 4 pints FFP and abdomen closed after keeping a drain. Single dose of inj methotrexate was given on day 5 . On day 14 ultrasonography was done which showed bulky uterus with scanty vascularity in placenta. Patient was discharged on day 15. On day 21, patient developed complaint of foul smelling vaginal discharge and fever. Patient was taken for examination under anesthesia, foul smelling discharge was coming out from cervix and profuse bleeding started on holding the cervix, interval hysterectomy was done .Patient received 4 pints of blood and 4 pints of FFP and two pints of platelets. Patient needed ionotropic support intraoperatively. Postoperatively for 2 days patient was in ICU and on ionotropic support. Patient developed wound infection which was treated with antibiotics. Patient was discharged on postoperative day 20 .

\section{RESULTS and LITERATURE REVIEW}

The mean age of patients was 25.5 years. Five cases presented in emergency in bleeding phase. One was a booked case and was admitted from 28 weeks of gestation and underwent elective LSCS at 37 weeks. All patients had h/o previous caesarean section. One patient had h/o suction and evacuation for missed abortion. In this case placenta had two lobes with superior lobe showing myometrial invasion at fundus of uterus. Four patients had previous ultrasound doppler findings suggestive of placenta previa with accreta. One had ultrasound with e/o placenta previa, accreta was not ruled out. Only one patient had MRI diagnosis of placenta percreta.

Two patients underwent elective LSCS at 39 wks and 37 wks of gestation.One had e/o myometrial invasion at fundus and caesarean hysterectomy was done. Second patient had e/o placenta percreta intraoperatively, placenta was left in situ after baby delivery. This patient required interval peripartum hysterectomy due to sepsis.

Conservative management was successful in two patients. Placenta was left in situ in these patients with stepwise devascularization done. Autolysis of placental tissue was 
monitored postoperatively by ultrasound doppler. Complete resorption of the placenta took 13-14 weeks postdelivery. One of these patients received single dose of injection Methotrexate.

In two patients emergency caesarean hysterectomy was done, one had placenta accreta and second had placenta increta.

Average blood loss was $2500 \mathrm{ml}$. Average requirement for whole blood and fresh frozen plasma was 4 pints each per patient. 3 patients needed ionotropic support and ICU monitoring postoperatively. Average hospital stay was 14.2 days postoperatively. Longest hospital stay(35 days)was for the patient who needed interval peripartum hysterectomy. This patient developed foul smelling vaginal discharge and sepsis in postoperative period, underwent hysterectomy, had placenta percreta.

2 babies required NICU admission due to prematurity, one of them had early neonatal death due to prematurity and very low birth weight of $1.2 \mathrm{kgs} .4$ babies were with mother.

\section{There was no maternal death in series.}

\section{DISCUSSION:}

The prevalence of placenta accreta spectrum has increased due to exponential increase in rate of caesarean section which is being most common risk factor ${ }^{(1,5,6)}$. Additional risk factors include advanced maternal age, multiparity, prior uterine surgeries or curettage, and Asherman syndrome ${ }^{(5,7,8)}$.Most favoured hypothesis is defect in the endometrial-myometrial interface that leads to failure of normal decidualization in the area of uterine scar which allows abnormally deep placental anchoring villi and trophobalast infiltration. Primary diagnostic modality for antenatal diagnosis is obstetric ultrasound. Most common ultrasonographic association of placenta accreta spectrum in second and third trimester is presence of placenta previa in more than $80 \%$ of cases in large series ${ }^{(9-11)}$. Other abnormalities include multiple vascular lacunae within the placenta, loss of normal hypoechoeic zone between placenta and myometrium, decreased retroplacental myometrial thickness(less than $\mathrm{l} \mathrm{mm}$ ), abnormalities of uterine serosa-bladder interphase and extension of placenta into myometrium, serosa and bladder ${ }^{(12,13)}$. Doppler ultrasound is effective to diagnose the PAS with sensitivity and specificity of $80 \%$ to $90 \%$ respectively.Turbulent lacunar flow is the common finding of the placenta accreta spectrum on colour flow doppler imaging

Magnetic resonance imaging may be useful for diagnosis of difficult cases such as posterior placenta previa and to assess depth of invasion in suspected percreta ${ }^{(14-16)}$.

Antenatal management of placenta accreta spectrum is critical as it provides an opportunity to optimize management and outcomes. Optimal management involves multidisciplinary team approach involving gynaecologist, anaesthetist, radiologist, urologist, paediatrician accustomed to the management of placenta accerta spectrum ${ }^{(17-18)}$

The treatment of placenta accrete is primarily surgical with hysterectomy being treatment of choice. A total hysterectomy is required as lower segment or cervical bleeding precludes supracervical hysterectomy ${ }^{(19)}$.

Uterine preservation and expectant management Expectant management is defined as leaving the placenta either partially or totally in situ. With expectant management, the cord is ligated near the placenta and the entire placenta is left in situ or only the placenta that spontaneously separates is removed before uterine closure. Conservative management can reduce complications like loss of future fertility, haemorrhage and injury to other pelvic organs ${ }^{(20,21)}$.Close monitoring during follow-up is mandatory for detecting any complications which may emerge weeks or months after delivery. Major complications found in our study were postpartum haemorrhage, massive blood transfusion, need for interval peripartum hysterectomy and wound sepsis.

The value of preoperative ureteric stent placement in cases with bladder involvement is unproven and left to case-by-case evaluation ${ }^{(17)}$. The role of pre operative placement of catheters or balloons into pelvic arteries for potential radiological occlusion is also controversial ${ }^{(22-24)}$.Iliac artery occlusion has been reported to decrease the blood flow in some but not all $\operatorname{cases}^{(22,25)}$.Serious complications like arterial damage, occlusion and infection may occur ${ }^{(26)}$, routine use is not recommended.

\section{Adjuncts to Conservative and Expectant Management}

Internal iliac artery ligation decreases the blood loss but efficacy is not proven and may be ineffective because of the formation of collaterals. The use of interventional radiology to embolise artery in case of persistent and uncontrolled haemorrhage may be useful.

Prophylactic tranexamic acid given at the time of delivery after cord clamping may reduce the risk of haemorrhage with placenta accrete spectrum.

Methotrexate use in expectant management of placenta accreta spectrum is advocated to hasten placental involution and resorption ${ }^{(27)}$. The biologic plausibility may be questioned because methotrexate targets rapidly dividing cells and division of third trimester placental cells is limited. Given the unproven benefit and possible harm, methotrexate to hasten placental resorption is not recommended ${ }^{(28)}$.

\section{Delayed Interval Hysterectomy}

Delayed interval hysterectomy may be needed in some cases managed expectantly.Patients with placenta percreta are optimal candidates for this procedure because they have an increased risk of blood loss and tissue damage if hysterectomy is performed at the time of cesarean delivery ${ }^{(29)}$.

\section{Future Fertility}

Expectant management of placenta accreta spectrum appears to have minimal effect on subsequent fertility but does carry a high recurrence risk of placenta accreta spectrum.

\section{CONCLUSION:}

Placenta accreta spectrum is nightmare for obstetrician which is increasing significantly. It is associated with maternal mortality and morbidity. Many risk factors are associated with adherent placenta most common association being previous caesarean delivery.Therefore it is desirable to take measures to reduce the rate of primary caesarean section and repeat caesarean section without increasing maternal and fetal risk. Measures include encouraging vaginal birth after caesarean section, avoiding caesarean section on demand after explaining remote complications of caesarean section like placenta accreta syndrome.

Timely diagnosis of placenta accreta is important and should be suspected in patients with previous caesarean section and placenta previa, high parity, previous uterine surgeries or curettage. Early diagnosis helps in optimizing the management of patient.

MRI is not mandatory in all cases of placenta accrete syndrome, can be useful in posterior placenta and to note the degree of invasion.

Scheduled delivery by cesarean section either with 
conventional or expectant management should be done according to availability of resources and patients condition. expectant management should be reserved for only those patients who can come for regular followup.

\section{Funding : No funding sources}

Conflict of interest : None declared

Ethical approval : Ethics approval - This is an observational study and data was obtained from clinical case records, Institutional Ethics Committee ( Government Medical College, Nagpur) has confirmed that no ethical clearance is needed.

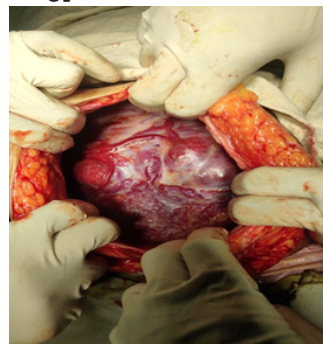

Fig l: a case of

placenta percreta placenta

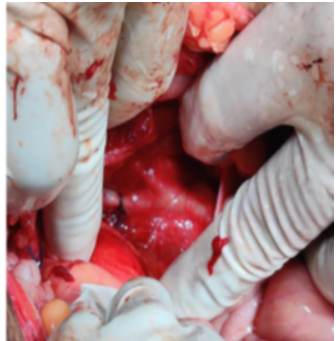

Fig 2 : Internal iliac artery ligation with dilated venous lakes invading upto serosa

\section{REFERENCES :}

1. Usta IM, Hobeika EM, Musa AA, Gabriel GE, Nassar AH. Placenta previaaccreta: risk factors and complications. Am J Obstet Gynecol 2005; 193:1045-9.

2. Shellhaas CS, Gilbert S, Landon MB, Varner MW, Leveno KJ, Hauth JC, et al. The frequency and complication rates of hysterectomy accompanying cesarean delivery. Eunice Kennedy Shriver National Institutes of Health and Human Development Maternal-Fetal Medicine Units Network. Obstet Gynecol 2009; 114:224-9.

3. Wu S, Kocherginsky M, Hibbard JU. Abnormal placentation: twenty-year analysis. Am J Obstet Gynecol 2005;192:1458-61.

4. Pundir J, Coomarasamy A. Gynaecology: Evidence-Based Algorithms. Cambridge, UK: Cambridge University Press; 2016.

5. Eshkoli T, Weintraub AY, Sergienko R, Sheiner E. Placenta accreta: risk factors, perinatal outcomes, and consequences for subsequent births. Am J Obstet Gynecol 2013;208:219.el-7.

6. Bowman ZS, Eller AG, Bardsley TR, Greene T, Varner MW, Silver RM. Risk factors for placenta accreta: a large prospective cohort. Am I Perinatol 2014:31:799-804

7. Garmi G, Salim R. Epidemiology, etiology, diagnosis, and management of placenta accreta. Obstet Gynecol Int 2012;2012:873929.

8. Baldwin HJ, Patterson JA, Nippita TA, Torvaldsen S, Ibiebele I, Simpson JM, et al. Antecedents of abnormally invasive placenta in primiparous women: risk associated with gynecologic procedures. Obstet Gynecol 2018;131:227-33

9. Eller AG, Bennett MA, Sharshiner M, Masheter C, Soisson AP, Dodson M, et al. Maternal morbidity in cases of placenta accreta managed by a multidisciplinary care team compared with standard obstetric care. Obstet Gynecol 2011;117:331-7.

10. Warshak CR, Ramos GA, Eskander R, Benirschke K, Saenz CC, Kelly TF, et al. Effect of predelivery diagnosis in 99 consecutive cases of placenta accreta. Obstet Gynecol 2010;115:65-9.

11. Shamshirsaz AA, Fox KA, Salmanian B, Diaz-Arrastia CR, Lee W, Baker BW, et al. Maternal morbidity in patients with morbidly adherent placenta treated with and without a standardized multidisciplinary approach. Am J Obstet Gynecol 2015:212:218.el-9.

12. Berkley EM, Abuhamad AZ. Prenatal diagnosis of placenta accreta: is sonography all we need? J Ultrasound Med 2013; 32: 1345-50

13. Comstock $\mathrm{CH}$, Bronsteen RA. The antenatal diagnosis of placenta accreta, BJOG 2014; 121:2

14. D'Antonio F, Iacovella C, Bhide A. Prenatal identification of invasive placentation using ultrasound: systematic review and meta-analysis. Ultrasound Obstet Gynecol 2013;42:509-17.

15. Gielchinsky Y, Mankuta D, Rojansky N, Laufer N, Gielchinsky I, Ezra Y. Perinatal outcome of pregnancies complicated by placenta accreta. Obstet Gynecol 2004;104:527-30.

5. 5.16.Esakoff TF, Sparks TN, Kaimal AJ, Kim LH, Feldstein VA, Goldstein RB, et al. Diagnosis and morbidity of placenta accreta. Ultrasound Obstet Gynecol 201Fl;37:324-7.

17. Eller AG, Porter TF, Soisson P, Silver RM. Optimal management strategies for placenta accreta. BJOG 2009; 116:648-54.

18. Silver RM, Barbour KD. Placenta accreta spectrum: accreta, increta, and percreta. Obstet Gynecol Clin North Am 2015;42:381-402.

19. Clark SL, Phelan JP, Yeh SY, Bruce SR, Paul RH. Hypogastric artery ligation for obstetric hemorrhage. Obstet Gynecol 1985;66:353-6.

20. Thurn L, Lindqvist PG, Jakobsson M, Colmorn LB, Klungsoyr K, Bjarnadottir RI, et al. Abnormally invasive placenta-prevalence, risk factors and antenatal suspicion: results from a large population-based pregnancy cohort study in the Nordic countries. BJOG 2016;123:1348-55. Article Locations:

21. Fox KA, Shamshiraj aa, Carusi D, secord AA, Lee P, Turan OM, et al, conservative management of morbidly adherent placenta : expert review. Am JObstet Gynaecol 2015; 213:755-60

22. Perez- Delboy A, Wright JD. Surgical management of placenta accreta: to leave or remove the placenta, BJOG 2014; 121:163-9:discussion 169-70

23. Shih JC, Liu KL, Shyu MK. Temporary balloon occlusion of the common iliac artery: new approach to bleeding control during cesarean hysterectomy for placenta percreta. Am J Obstet Gynecol 2005;193:1756-8

24. Greenberg JI, Suliman A, Iranpour P, Angle N. Prophylactic balloon occlusion of the internal iliac arteries to treat abnormal placentation: a cautionary case. Am J Obstet Gynecol 2007; 197:470.el-4.

25. Shrivastava V, Nageotte M, Major C, Haydon M, Wing D. Case-control comparison of cesarean hysterectomy with and without prophylactic placement of intravascular balloon catheters for placenta accreta. Am Obstet Gynecol 2007; 197:402.el-5.

26. Bishop S, Butler K, Monaghan S, Chan K, Murphy G, Edozien L. Multiple complications following the use of prophylactic internal iliac artery balloon catheterisation in a patient with placenta percreta. Int J Obstet Anesth 2011;20:70-3.

27. Ramoni A, Strobl EM, Tiechl J, Ritter M, Marth C. Conservative management of abnormally invasive placenta: four case reports. Acta Obstet Gynecol Scand 2013;92:468-71.

28. Fox KA, Shamshirsaz AA, Carusi D, Secord AA, Lee P, Turan OM, et al Conservative management of morbidly adherent placenta: expert review. Am JObstet Gynecol 2015;213:755-60.

29. Clausen C, Lonn L, Langhoff-Roos J. Management of placenta percreta: a review of published cases. Acta Obstet Gynecol Scand 2014;93:138- 